\title{
A community-based intervention to increase participation in cervical cancer screening among immigrants in Norway
}

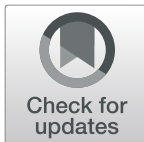

Samera A. Qureshi ${ }^{1 *}$ D, Abdi Gele ${ }^{1}$, Prabhjot Kour ${ }^{1,2}$, Kathy A. Møen ${ }^{1,3}$, Bernadette Kumar $^{1}$ and Esperanza Diaz ${ }^{1,3}$

\begin{abstract}
Background: The attendance to cervical cancer screening is low among immigrants in many high-income countries. Although several interventions have been experimentally tested,implementation remains a challenge. Several factors are an impediment, including the lack of methodological descriptions of the development and implementation of such interventions. In this paper,we present in detail the development, methodological challenges and practical implementation of a community based intervention aimed to increase the participation of immigrant women in cervical cancer screening in Norway.

Methods: This study was initially designed as a cluster randomized trial to be carried out in four geographical areas near Oslo between Feb-October 2017. Participants were immigrant women aged 25-69 years from Pakistan and Somalia. This paper describes the theoretical background for the development of the intervention,followed by challenges,the changes in the original design and solutions adopted related to the study design,recruitment and implementation of the intervention. The intervention was developed based on two theoretical frameworks, the Ecological and the Heron's six categories intervention framework. An oral 20-25 min presentation in the language of participants encompassing topics of cervical cancer and screening was given according to the needs detected in focus groups conducted at the beginning of the study,followed by an opportunity to raise questions and answering a short questionnaire.

Results: Contrary to the initial study design, this had to be converted into a non-randomised trial due to the difficulties associated with randomization of immigrant families who are finely scattered in heavily populated towns and a high risk of contamination. We therefore adopted a pragmatic approach and recruited women in the intervention areas through a variety of channels and institutions. Neighboring areas were considered to be nonrandomised controls. Female researchers with Pakistani and Somali background invited as many women as possible in the intervention areas. Among the women who were invited to participate, $42 \%$ of the Pakistani and $78 \%$ of Somali attended the meetings.

Conclusion: Despite the careful development of a culturally adapted health intervention in collaboration with the community; randomization and recruitment of immigrants for community trials remains challenging. Nevertheless, sharing strategies to overcome specific challenges related to promoting health interventions for immigrants, can be of potential help to scale-up interventions and for building new research projects.
\end{abstract}

Trial registration: NCT03155581. Retrospectively registered, on 16 May 2017.

Keywords: Immigrants, Community-based, Cervical Cancer, Screening, Methods

\footnotetext{
* Correspondence: sameraazeem.qureshi@fhi.no

${ }^{1}$ Norwegian Centre for Migrant \& Minority Health (NAKMI), Norwegian

Institute of Public Health (NIPH), P.O.Box 222 Skøyen, 0213 Oslo, Norway

Full list of author information is available at the end of the article
}

(c) The Author(s). 2019 Open Access This article is distributed under the terms of the Creative Commons Attribution 4.0 International License (http://creativecommons.org/licenses/by/4.0/), which permits unrestricted use, distribution, and reproduction in any medium, provided you give appropriate credit to the original author(s) and the source, provide a link to the Creative Commons license, and indicate if changes were made. The Creative Commons Public Domain Dedication waiver (http://creativecommons.org/publicdomain/zero/1.0/) applies to the data made available in this article, unless otherwise stated. 


\section{Background}

Cervical cancer is the second most commonly diagnosed cancer and third leading cause of cancer deaths among females worldwide [1]. A substantial number of cervical cancer cases and deaths can be prevented if screened and detected early. Screening programs in high-income countries have reduced cervical cancer rates up to $65 \%$ over the past 40 years [2]. This is in contrast to countries like Somalia where the rates continue to remain high $(34.8 / 100,000)$ [1]. This high prevalence of cervical cancer in middle- and low-income countries is largely attributed to either the absence of an organized screening program or a low uptake of screening tests [3, 4].

Immigrant women residing in high-income countries have lower participation in screening tests as compared to the general population [5] . Similarly, in Norway screening uptake among the majority population is higher than among immigrant women (Immigrants were defined based on the definition given by the SSB "Immigrants are defined as those born outside of Norway to one or two foreign-born parents and four foreign-born grandparents") [6]. Women, especially from Somalia, who are among the largest non-Western immigrant groups in Norway, have specifically been observed to have low attendance rates [7]. Though several intervention studies have been conducted to increase the cervical cancer screening attendance among immigrant women in high-income countries [8-11], the results are modest as participation of immigrant women still remains generally low.

Our recent study [12] among Pakistani and Somali immigrant women in Norway, documented individual, sociocultural and health system-related barriers that prevent these women from undergoing screening tests. In parallel, health care professionals interviewed in order to obtain their views regarding the reasons for low attendance to the cervical cancer screening program contributed with knowledge about specific barriers with immigrants [6]. Building upon the opinions and wishes of both groups, we developed an intervention specifically targeting women from Pakistan and Somalia. Although we intended to learn from previous intervention studies with similar aims, our literature review showed that previous intervention studies often lack a detailed description of the design, reliable elements of the intervention itself and its implementation [13, 14]. Also in other health care interventions targeting immigrants, authors seldom provide detailed descriptions about the process of development and implementation of interventions, what functioned well and what went wrong [15]. We tried In order to fill this gap and to aid the advancement of future studies, this paper describes both the development and implementation of a randomised communitybased intervention among immigrant women of
Pakistani and Somali background living in Norway, along with the process, challenges faced and strategies used to overcome them.

\section{Methods}

Although the CONSORT guidelines for clinical trials (http://www.consort-statement.org/) is not applicable to our manuscript as described in detail below, but we have tried to adhere to the checklist as much as possible.

\section{Study design and randomization}

This intervention study was originally designed as cluster randomised intervention study, and geographic areas were randomized as clusters. Selection of the geographical areas was based on the number of immigrant women residing there. Sample size was calculated for an increase in cancer screening participation from 0.45 to 0.55 with $80 \%$ power and $5 \%$ significance level. We tried several intra class correlation (ICC) levels, and ended-up dividing the area in 16 clusters that were matched according to the calculated number of female immigrants aged 20 to 69 from Somalia and Pakistan. In our study, all women from Somalia and Pakistan living in the intervention clusters were meant to comprise the intervention groups; immigrant women from the same countries of origin living in control clusters were to be control participants. An estimated 625 and 915 women [16] from Somalia and Pakistan respectively lived in the study area (Akershus and Buskerud). Approximately half of the women from each county were to be in the intervention clusters. After assuring that the cluster-areas were not naturally linked by a mosque or other natural known gathering centre for these populations by looking in a map, clusters were randomly assigned to intervention or control groups.

In the following we will describe 1) the intervention and its elements, 2) the challenges and solutions related to the study design, and recruitment of participants and 3) a description of the actual participants in the intervention based on a short questionnaire applied at the end of the intervention. Information from this questionnaire was entered into excel sheet, and transferred to Stata for analysis. All procedures adopted ensured confidentiality and were according to approval of the ethical committee. The participants gave verbal consent for participation and written consent was not deemed necessary as we did not collect any sensitive information (name, address etc.) and no invasive procedures were conducted.

\section{Results}

The intervention and its elements

This community-based intervention was developed based on the Ecological framework identified in our previous study [12, 17] and the Heron's six category 
intervention framework (Fig. 1) [18]. This conceptual framework was developed by John Heron [19-21] and classifies interventions in six categories: prescriptive (advice), informative, confronting (challenging), cathartic (enabling the expression of pent-up emotions), catalytic ('drawing out') and supportive (confirming or encouraging). Heron's model is considered as being conceptual for understanding interpersonal relationships, as well as an assessment tool for identifying a range of possible therapeutic interactions between two people [22]. The main purpose of using the Heron's model here is that we wanted the women to be interactive during the intervention in order to challenge the information being given to them. This would further allow us to address their confusions and thus help and motivate them to participate in screening. Based on the presented theoretical concepts, the factors identified by focus group discussions $(6,12)$ and in consultation with the research group, we developed an intervention consisting of an informative power-point presentation of 20-25 min (Additional file 1). The presentation content started from a more general description of our project aims followed by brief information on healthy lifestyle and preventative health care and then narrowing it down to cervical cancer. In very simple language (Somalia or Urdu), we explained what do we mean by cervical cancer, its anatomical location -through diagrammatic illustration-, causes, risk factors, and development, This was followed by practical information on cervical cancer screening including the procedure itself and the instruments used, which were also shown physically. A short video clip of the test being done was played. After the video clip the women were informed about the Norwegian screening guidelines for cervical cancer. Towards the end the women were given information on how to book an appointment with their GP's for taking a screening test, including the payment. The content of the presentation (power point) was both in English and in the respective languages (Urdu and Somali). At the end of the meetings, we distributed a simple questionnaire (Additional file 2) among the participants to obtain demographic data and information regarding previous attendance to cervical cancer screening and knowledge about the health system presented in Table 1. During the refreshment session after the intervention, the researchers intermingled with the participants to chat about whether the information given to them was helpful in their understanding of the problem and if they would actually go for the screening after attending this session.

The intervention was conducted separately for the Somali and Pakistani communities, in venues (community centre) located in each of the setting areas, depending on the availability and the convenience for the participants. The intervention was conducted by the principal author for the Pakistani group, in collaboration with another female assistant. For the Somali group, a female fieldworker recruited the participants and was present at the meetings, but the intervention was led by a male Somali nurse who had previously been involved in other intervention projects among the Somali women and who is popular within the community.

\section{Challenges and solutions related to the study design and recruitment \\ Study design}

As explained in the methods, our intervention study was originally designed as a community-based cluster randomised intervention study. However, as both groups of immigrants meet each other relatively often due to family or group reunions. Further, when we started the recruitment, we realized that it was difficult to locate immigrant households as they are finely dispersed across the study areas. In addition to that keeping the intervention and control group separate to avoid contamination was also a challenge, because frequent interaction among immigrants' is much more existent as compared to the majority population. Therefore, after long discussion with researchers and research assistants, it was

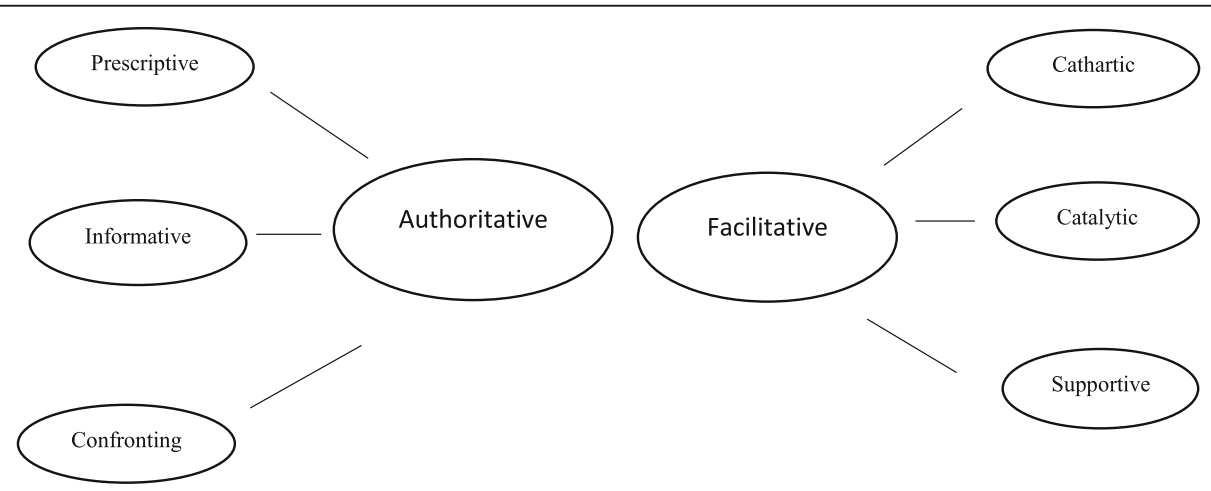

Fig. 1 The Heron's six category intervention framework. Authoritative and facilitative categories by Heron 
Table 1 Characteristics of the study participants. Characteristics of Pakistani and Somali women who attended the meetings

\begin{tabular}{|c|c|c|}
\hline Variables & Pakistani $n=102(\%)$ & Somali $n=128(\%)$ \\
\hline \multicolumn{3}{|l|}{ Age (years) } \\
\hline$<25$ & $1(0.98)$ & $12(9.3)$ \\
\hline $25-45$ & $67(66.7)$ & $97(75.7)$ \\
\hline $46-69$ & $31(30.4)$ & $17(13.2)$ \\
\hline $70+$ & $3(2.94)$ & $1(0.8)$ \\
\hline \multicolumn{3}{|l|}{ Number of Children } \\
\hline 0 & $5(4.9)$ & $29(22.6)$ \\
\hline 1 & $8(6.9)$ & $15(2.6)$ \\
\hline 2 & $20(18.7)$ & $19(14.8)$ \\
\hline $3+$ & $69(67.7)$ & $62(48.4)$ \\
\hline \multicolumn{3}{|l|}{ Marital status } \\
\hline Single & $6(5.7)$ & $15(2.6)$ \\
\hline Married & $87(86.2)$ & $59(46.1)$ \\
\hline Separated/Divorced/Widow & $9(7.9)$ & $45(35.1)$ \\
\hline \multicolumn{3}{|l|}{ Country of birth } \\
\hline Pakistan & $76(75.6)$ & - \\
\hline Somalia & - & $123(96.1)$ \\
\hline Norway/other & $26(25.6)$ & $4(3.1)$ \\
\hline \multicolumn{3}{|l|}{ Language } \\
\hline Urdu/Somali & $34 /-(32.9)$ & $-/ 112(87.5)$ \\
\hline Norwegian & $5(4.9)$ & - \\
\hline Norwegian/Urdu/Somali & $43(41.9)$ & $10(7.8)$ \\
\hline Norwegian/Urdu/Punjabi/English & $20(19.7)$ & $2(1.5)$ \\
\hline \multicolumn{3}{|l|}{ Years of school $\left.\right|^{a}$} \\
\hline No school & $12(11.7)$ & $21(16.4)$ \\
\hline$\leq 11$ & $14(13.6)$ & $41(32.3)$ \\
\hline $12-14$ & $38(37.6)$ & $51(39.2)$ \\
\hline $15+$ & $35(34.7)$ & $6(4.6)$ \\
\hline \multicolumn{3}{|l|}{$P$ for trend } \\
\hline \multicolumn{3}{|c|}{ Do you know how to make an appointment with your GP? } \\
\hline Yes & $90(89.6)$ & $103(80.4)$ \\
\hline No & $12(11.9)$ & $21(16.4)$ \\
\hline \multicolumn{3}{|l|}{ Have you ever taken a screening test? } \\
\hline Yes & $73(72.7)$ & $58(45.3)$ \\
\hline No & $29(28.4)$ & $68(51.7)$ \\
\hline \multicolumn{3}{|l|}{ How long ago } \\
\hline Never & $29(28.4)$ & $68(51.7)$ \\
\hline 1 year & $26(25.7)$ & $19(14.8)$ \\
\hline $2+$ years & $47(46.0)$ & $42(32.7)$ \\
\hline
\end{tabular}

After this meeting, do you think you should contact your general practitioner to take a screening test?

$\begin{array}{lll}\text { Yes } & 79(77.4) & 116(90.6) \\ \text { No } & 23(21.9) & 12(9.3)\end{array}$

How often do you need to have someone help you when you read instructions, pamphlets, or other written material from your doctor or pharmacy? Never $60(59.2)$

$72(56.2)$ 
Table 1 Characteristics of the study participants. Characteristics of Pakistani and Somali women who attended the meetings (Continued)

\begin{tabular}{lll}
\hline Variables & Pakistani $n=102(\%)$ & Somali $n=128(\%)$ \\
\hline Always & $12(11.9)$ & $19(14.9)$ \\
Sometimes & $13(12.1)$ & $21(16.4)$ \\
Rarely & $16(15.8)$ & $15(11.8)$ \\
\hline
\end{tabular}

${ }^{\mathrm{a}}$ No school(no education); $\leq 11$ years (Elementary school); 12-14 years (High School);15+ (University Level)

decided to drop randomization as planned, and adopt direct recruitment of women from different community institutions, households, and religious sites in the every area as a whole. The adjacent areas were then redefined as non-randomised controls.

\section{Recruitment}

The intervention was carried out from Feb - October 2017. Although we intended to finish by May, but the recruitment was hindered first by the Easter holidays (it is quite a common practice in Norway that immigrants travel to their home countries during the Easter vacations as the schools are closed for almost 2 weeks), during which a lot of women were travelling. Secondly, the holy month of Ramadhan and the summer vacation forced us to extend our intervention period to October. The principal author, a senior researcher of Pakistani origin, approached the women by mobilizing different channels such as Pakistani organizations and community centres to identify one informant in each of the four areas. After a time consuming process, including use of personal social circle and involvement of organization or community centres, including the Imams of the mosques in the study areas in the intervention areas, four key informants were recruited, and they further recruited participants through different channels such as personal phone calls, community gatherings and social media (Facebook). Women who did not show up for the first meeting despite having agreed to it, were contacted again to attend the second meeting through personal visits, phone calls and through women who attended the first meeting.

A Somali female research assistant was hired for the recruitment of the Somali women. She contacted women in her network in these four areas over the telephone, informed them about the intervention meeting and asked whether they were willing to participate. These women then provided contact information of other women in their network. The women who did not show up for the first meeting were visited by the research assistant at their homes to ask them to attend the next meeting.

As an incentive for participation we offered two lottery gift cards each worth NOK 500 after every meeting, in addition to serving of tea, coffee and refreshments etc.
We offered an air ticket to Pakistan and Somalia for one woman from each of the respective groups drawn by lottery. The reason for this incentive was to motivate the participation of the target communities to the intervention.

\section{Participants}

Among the 915 Pakistani and 625 Somali women, who were living in these areas as indicated by The Statistics Norway (SSB), the key informants managed to invite a total of $401(42 \%$ of the Pakistani) and 485 (78\% of Somali) women to one of the seven meetings arranged for each group. The Pakistani women who attended the meetings were 102 (11.5\% of the total and $25 \%$ of invited), while the Somali women were 128 (14\% of the total and $26 \%$ of invited).

The characteristics of the participants are presented in Table 1 . This data was collected through the questionnaire distributed after the meeting and was answered by all the women who attended the meeting. The majority of the women from both countries attending the meetings were in the middle aged, married and had three or more children. The number of separated and divorced women was greater among Somali women. Pakistani women had secondary or higher education and the majority had taken a cervical cancer screening test at least once, while less than half of the Somali women had attended secondary or higher education, and only $45 \%$ had ever gone for a screening test.

Table 2 shows the questions asked by the participants grouped in three categories: cervical cancer, cervical cancer screening test and Human papilloma virus (HPV).

\section{Discussion}

This intervention study was the first of its kind to be carried out among the two main immigrant groups in Norway. The intervention itself had a combination of elements that have been reported to be successful in other intervention studies carried out among immigrants in other parts of the world [23-25].

The intervention's theoretical basis was Heron's framework and the results of our earlier study using the ecological framework. Following the Heron's theory, the intervention can be mainly seen as prescriptive and informative, as we tried to give the participants advice on 
Table 2 Questions asked by the participants grouped in three categories. Questions raised by the participating women

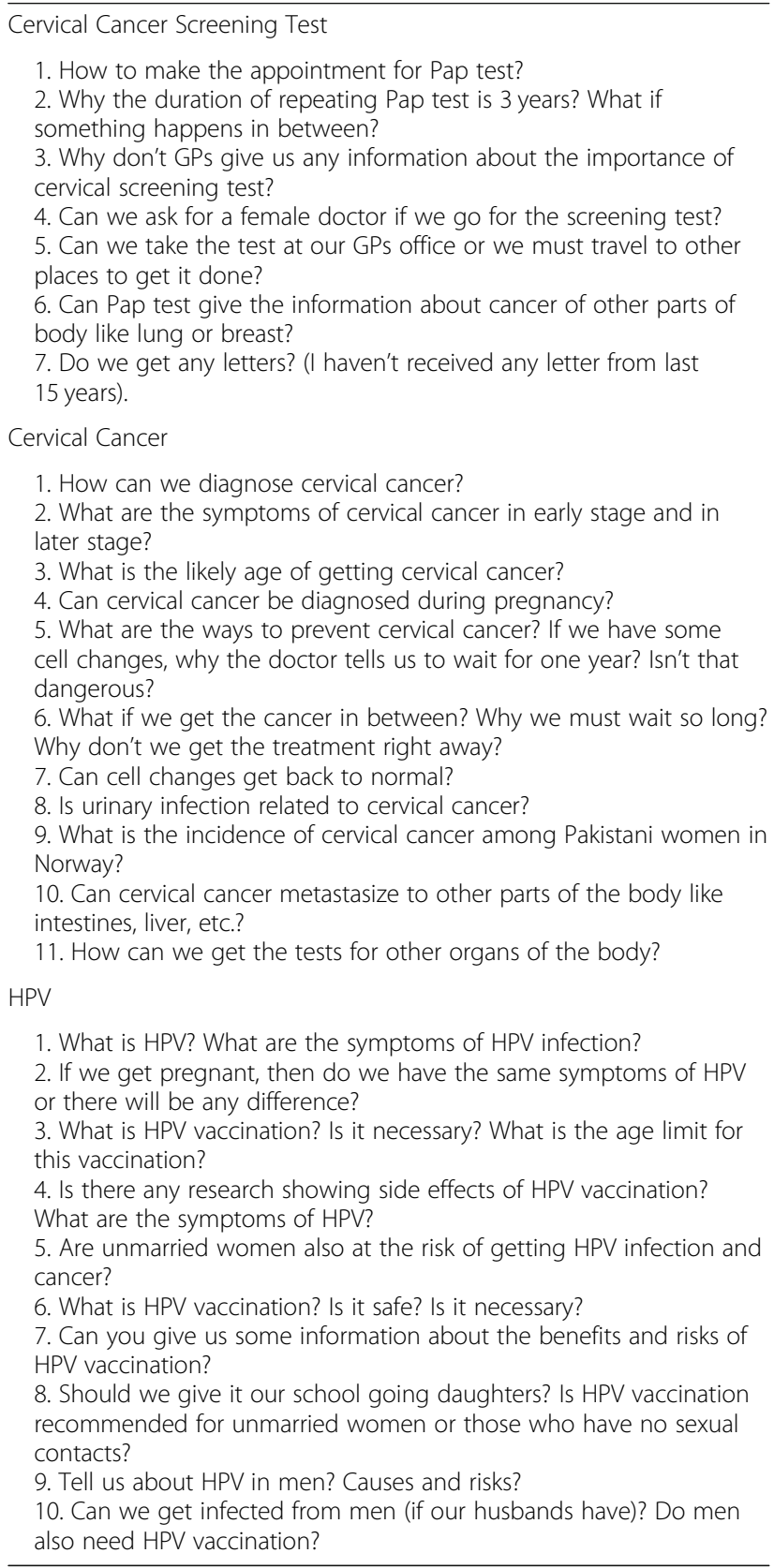

the uptake of pap-smear, and objective information about the benefits of participating in the screening program and harms of non-participation and instructions on how to proceed. From the facilitative point of view, our intervention was mainly supportive and motivational, as we tried to answer questions and fears expressed by the women. As regards the cathartic and catalytic elements, we allowed the participants to express their experiences, anger, hesitations during the interactive meeting, and being judgemental in deciding whether to participate in the screening program or not.
Through these elements we have tried in every possible way to encourage the women in participating in the screening program without being authoritative or confronting, but helping them in making a personal informed choice for participation considering both the harms of not participating and benefits of participation.

The first practical challenge was related to the high probability of contamination linked to the division of areas in randomization and control areas. The groups of migrants we chose have extensive internal networks that were broader than our defined areas. For this reason we had to extend the areas, and thus lost randomization even though we had explored previously the existence of mosques or immigrant shops in between. The lesson to learn from this is, although we were geographically able to identify immigrant majority areas but we should not forget the tight bonds that exist within the immigrant groups, which extend beyond the geographical boundaries.

The second challenge was related to the recruitment of women. This is in accordance with many other studies that have highlighted the methodological challenges of recruiting minority groups into research trials [2629]. As previously reported by our group, the researcher should always try to develop a trust relationship with the participants, rather than just showing up at the door for recruitment purpose [15]. One strategy to overcome this fear is to have researchers from the same ethnic background to eliminate the element of mistrust and we adopted this strategy in our intervention. Also, we adopted community-based recruitment through immigrant organizations, mosques etc. in addition to recruitment through personal contacts. All these strategies have been reported as being helpful in trial settings [29]. Still, the attendance to the meetings was approximately one in four invited. Furthermore, the majority of young educated women had the opinion that a lot of this information can also be obtained from the internet, thus making it unnecessary to attend such meetings. However, among those who attended, we were able to ensure a highly diverse group regarding their level of education, age, and marital status and this information did attract the attention of older and uneducated women who are not familiar with digital technology and who probably have the lowest attendance to screening tests. Last, we encouraged diffusion of information whereby women who participated in the study will hopefully pass the information to others in their neighborhood.

The current intervention was a culturally adapted intervention in many respects, including targeting of language, gender, venue and development of material. Similar to our intervention study, other intervention have also been carried out among other immigrant groups [8-11, 23-25]. The majority of them were community based and included the use of community lay- 
health workers, linguistically-appropriate and culturallytailored educational materials or navigation assistance to overcome the barriers to access the services. These interventions have resulted in increase in awareness and knowledge about cervical cancer with increase in screening participation [23]. Although we did not use community health workers for our intervention method, we did ensure that it was linguistically and culturally appropriate. Unlike other studies, we did not use written educational materials as women during the focus group discussion pointed out that sending of brochures, letters etc. would not be helpful. Rather, they wanted to have information given to them in seminar presentations by professionals. This strategy seems to have been correct in the light of our data, since approximately $30 \%$ among the women attending the meetings were unable to read any type of health related letters, brochures, posters etc. Similarly, the immigrant groups involved in this intervention came from oral and visual cultures, i.e. cultures that learn through listening and watching, and not through reading or writing. Inadequate health literacy among immigrant women has been reported by previous studies [30, 31].

Among the participating women, 25\% had never taken cervical cancer screening test despite $81 \%$ of the women had children and it is a common practice to take a cervical test during antenatal visits. Several factors might explain this fact. The type of questions raised by the participants after the seminars points to a low level of awareness and knowledge regarding screening test among the women. This has also been reported by other studies [32]. Therefore, the information given by the researcher focused on cervical cancer in general, to raise the awareness and basic knowledge among the women. Lack of information given by the GPs to some immigrant groups has also been reported by our group (Møen, 2018 submitted). Additionally, as explained above, low health literacy and lack of knowledge about the health care system were widespread among the women. At the same time women had also expressed in the previous focus groups that they did not pay attention to the invitation letter sent by the cancer registry. We tried to address all these issues in our intervention. Once women got some information, the participants wanted to know more about the disease and its causes and how it could be prevented. After the presentation women seemed to realize the importance and sensitivity of the issue, as shown by the data that $78 \%$ of Pakistani whereas $90 \%$ of the Somali women replied that they will contact the GP for the test after attending this meeting.

Majority of the women who did not agree to take a pap smear were those who had already undergone screening either in the previous year (26\% Pakistani \& 15\% Somali) or 2 years ago (46\% Pakistani \& 33\% Somali). However, most Somali and Pakistani immigrants in Norway have challenges in coping with the new way of life in their host country. Solving their day-to-day problems in life may divert their attention away from participation in health programs and research and intention to take the test does not necessarily change behavior.

In order to see the effect of our intervention we plan to measure the effect of the intervention between the intervention and control areas by analysing the data from the national cancer register which records personal information on cervical cancer screening.

\section{Conclusions}

We have developed and implemented an intervention among immigrant women to increase their participation in cervical cancer screening following the existing recommendations for culturally adapted studies. Still, we confronted methodological and recruitment challenges that are described in this paper for the future advancement of the field. Although we had initially designed it to be a randomized controlled trial, we had to restrict ourselves to a community-based intervention with a non-randomised control group to avoid contamination. This is to say, we had to give up randomisation which is considered to be an important component of intervention studies.

Behavioural interventions are complex and when targeting them to immigrants adds further complexity [33]. However, it is of fundamental importance to recognise the specificity of promoting health interventions within immigrant populations. Although, such intervention methods are more time consuming, need extensive resources and personal commitment, we hope to demonstrate in the near future that the effectiveness of interventions such as ours provides basis for the justification and commitment of resources to this approach in health promotion research. We further hope that this intervention will allow future researchers to learn from our experience and challenges and eventually develop more targeted interventions for immigrant groups.

\section{Additional files}

Additional file 1: Questionnaire. (PDF $445 \mathrm{~kb}$ )

Additional file 2: Power Point presentation. (PDF 2210 kb)

\section{Acknowledgments}

The authors wish to thank Ubah Abshir and Muhammad Sheldon for carrying out the intervention among the Somali participants, as well as the Pakistani contacts in Lørenskog (Shahnaz), Asker (Sughran Bibi), Bærum (Sadia Ghafoor) and Drammen (Sobea Chaudry) for collaborating with the study team. Last, thanks are also due to the participants of the study for their participation and help.

Author's contributions

SAQ and PK conducted the intervention. ED and BK designed the study. ED had overall responsibility for the study. SAQ analysed the data and drafted 
the manuscript. AG and KAM also contributed in analyses and editing of the manuscript. All authors were responsible for editing and improvement of the manuscript. All authors gave approval for the final version of the manuscript.

\section{Funding}

The project was funded by the Norwegian Cancer Society. However, the corresponding author did not receive any financial compensation for this manuscript. Kathy Moen is a PhD candidate for this project with grant from the Norwegian Cancer Society.

\section{Availability of data and materials}

The dataset used and analysed during the current study are available from the corresponding author on request.

\section{Ethics approval and consent to participate}

The project was approved by "The Norwegian Regional Committees for Medical and Health Research Ethics". We did not feel the need for a written consent as the intervention was just giving information and we only required the presence of the participants and this was approved by the ethics committee as stated above. During the intervention stage, it was mostly us that gave information at the meetings. In addition the questionnaires they answered had this text "By answering this questionnaire you accept that we use this information only for the purpose explained to you All information will be treated in strict confidence".

\section{Consent for publication}

As our manuscript does not include any individual data or sensitive personal information, therefore consent for publication is "Not Applicable" in this case.

\section{Competing interests}

The authors report no conflicts of interest in this work.

\begin{abstract}
Author details
${ }^{1}$ Norwegian Centre for Migrant \& Minority Health (NAKMI), Norwegian Institute of Public Health (NIPH), P.O.Box 222 Skøyen, 0213 Oslo, Norway. ${ }^{2}$ Norwegian National Advisory Unit on Concurrent Substance Abuse and Mental Health Disorders, Innlandet Hospital Trust, P.O.Box 104, 2381 Brumunddal, Norway. ${ }^{3}$ Department of Global Public Health and Primary Care, University of Bergen, P.O.Box 7804, N-5020 Bergen, Norway.
\end{abstract}

Received: 25 September 2018 Accepted: 3 July 2019

\section{Published online: 12 July 2019}

\section{References}

1. Estimated Cancer Incidence Mortality and Prevalence Worldwide in 2012 [Internet]. WHO. 2012

2. Torre LA, Bray F, Siegel RL, Ferlay J, Lortet-Tieulent J, Jemal A. Global cancer statistics, 2012. CA Cancer J Clin. 2015;65(2):87-108.

3. Ghebre RG, Sewali B, Osman S, Adawe A, Nguyen HT, Okuyemi KS, et al. Cervical cancer: barriers to screening in the Somali community in Minnesota. J Immigr Minor Health. 2015;17(3):722-8.

4. Johnson CE, Mues KE, Mayne SL, Kiblawi AN. Cervical cancer screening among immigrants and ethnic minorities: a systematic review using the health belief model. Journal of lower genital tract disease. 2008;12(3):232-41.

5. Leinonen MK, Campbell S, Ursin G, Trope A, Nygard M. Barriers to cervical cancer screening faced by immigrants: a registry-based study of 1.4 million women in Norway. Eur J Pub Health. 2017;27(5):873-9.

6. Moen KA, Kumar B, Qureshi S, Diaz E. Differences in cervical cancer screening between immigrants and nonimmigrants in Norway: a primary healthcare register-based study. Eur J Cancer Prev. 2017;26(6):521-7.

7. Morrison TB, Flynn PM, Weaver AL, Wieland ML. Cervical cancer screening adherence among Somali immigrants and refugees to the United States. Health Care Women Int. 2013;34(11):980-8.

8. Nguyen TT, McPhee SJ, Gildengorin G, Nguyen T, Wong C, Lai KQ, et al. Papanicolaou testing among Vietnamese Americans: results of a multifaceted intervention. Am J Prev Med. 2006:31:1):1-9.

9. Wang X, Fang C, Tan Y, Liu A, Ma GX. Evidence-based intervention to reduce access barriers to cervical cancer screening among underserved Chinese American women. Journal of women's health (2002). 2010;19(3):463-9.

10. Mock J, McPhee SJ, Nguyen T, Wong C, Doan H, Lai KQ, et al. Effective lay health worker outreach and media-based education for promoting cervical cancer screening among Vietnamese American women. Am J Public Health 2007:97(9):1693-700.

11. Olsson E, Lau M, Lifvergren S, Chakhunashvili A. Community collaboration to increase foreign-born women's participation in a cervical cancer screening program in Sweden: a quality improvement project. Int J Equity Health. 2014;13:62

12. Gele AA, Qureshi SA, Kour P, Kumar B, Diaz E. Barriers and facilitators to cervical cancer screening among Pakistani and Somali immigrant women in Oslo: a qualitative study. Int J Women's Health. 2017:9:487-96.

13. Michie S, Abraham C, Whittington C, McAteer J, Gupta S. Effective techniques in healthy eating and physical activity interventions: a metaregression. Health psychology : official journal of the Division of Health Psychology, American Psychological Association. 2009;28(6):690-701.

14. Michie S, Ashford S, Sniehotta FF, Dombrowski SU, Bishop A, French DP. A refined taxonomy of behaviour change techniques to help people change their physical activity and healthy eating behaviours: the CALO-RE taxonomy. Psychol Health. 2011:26(11):1479-98.

15. Terragni L, Beune E, Stronks K, Davidson E, Qureshi S, Kumar B, et al. Developing culturally adapted lifestyle interventions for south Asian migrant populations: a qualitative study of the key success factors and main challenges. Public Health. 2018;161:50-8.

16. Statistics Norway. 2017

17. McLeroy KR, Bibeau D, Steckler A, Glanz K. An ecological perspective on health promotion programs. Health Educ Q. 1988:15(4):351-77.

18. Heron J. Helping the client; a creative practical guide: Fifth. ed2001.

19. Heron J. Six Category Intervention Analysis. Human Potential Research Project. University of Surrey, Guildford; 1975.

20. Heron J. Six category intervention analysis. Human potential research project. 2nd ed1986.

21. Blake R, Mouton JS. Consultation. New York: Addison Wesley; 1976.

22. Burnard P, Morrison P. Nurses' perceptions of their interpersonal skills: a descriptive study using six category intervention analysis. 1988. Nurse Educ Today. 2005:25(8):612-7 discussion 8-9.

23. Duffy SW, Myles JP, Maroni R, Mohammad A. Rapid review of evaluation of interventions to improve participation in cancer screening services. J Med Screen. 2017;24(3):127-45.

24. Lu M, Moritz S, Lorenzetti D, Sykes L, Straus S, Quan H. A systematic review of interventions to increase breast and cervical cancer screening uptake among Asian women. BMC Public Health. 2012;12:413.

25. Soares MB, Silva SR. Interventions that facilitate adherence to pap smear exam: integrative review. Rev Bras Enferm. 2016;69(2):404-14.

26. UyBico SJ, Pavel S, Gross CP. Recruiting vulnerable populations into research: a systematic review of recruitment interventions. J Gen Intern Med. 2007:22(6):852-63.

27. Banda DR, Germain DS, McCaskill-Stevens W, Ford JG, Swain SM. A critical review of the enrollment of black patients in cancer clinical trials, vol. 2012: American Society of Clinical Oncology educational book American Society of Clinical Oncology Meeting. p. 153-7.

28. Samsudeen BS, Douglas A, Bhopal RS. Challenges in recruiting south Asians into prevention trials: health professional and community recruiters' perceptions on the PODOSA trial. Public Health. 2011;125(4):201-9.

29. Douglas A, Bhopal RS, Bhopal R, Forbes JF, Gill JM, Lawton J, et al. Recruiting south Asians to a lifestyle intervention trial: experiences and lessons from PODOSA (prevention of Diabetes \& Obesity in south Asians). Trials. 2011:12:220.

30. Gele AA, Pettersen KS, Torheim LE, Kumar B. Health literacy: the missing link in improving the health of Somali immigrant women in Oslo. BMC Public Health. 2016;16(1):1134.

31. Jordan S, Hoebel J. Health literacy of adults in Germany: findings from the German health update (GEDA) study. Bundesgesundheitsblatt, Gesundheitsforschung, Gesundheitsschutz. 2015:58(9):942-50.

32. Crawford J, Ahmad F, Beaton D, Bierman AS. Cancer screening behaviours among south Asian immigrants in the UK, US and Canada: a scoping study. Health \& social care in the community. 2016;24(2):123-53.

33. Resnicow K, Baranowski T, Ahluwalia JS, Braithwaite RL. Cultural sensitivity in public health: defined and demystified. Ethnicity \& disease. 1999:9(1):10-21.

\section{Publisher's Note}

Springer Nature remains neutral with regard to jurisdictional claims in published maps and institutional affiliations. 